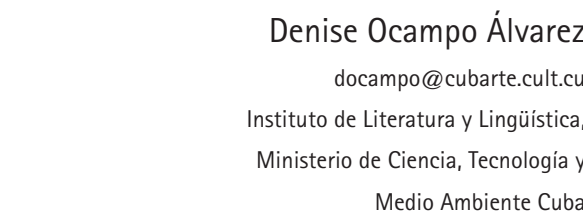

(Recibido: 1 de junio de 2019/ Received: $1^{\text {st }}$ June 2019) (Aceptado: 5 septiembre 2019 / Accepted: $5^{\text {th }}$ September 2019)

\section{CULTURA Y PRIORIDAD SOCIOPOLITICA. ORGANIZACIÓN DE FUNCIONES EN LA LITERATURA INFANTIL Y JUVENIL CUBANA}

\author{
CULTURE AND SOCIOPOLITICAL PRIORITY. \\ ORGANIZATION OFFUNCTIONS IN CUBAN \\ LITERATURE FOR CHILDREN
}

\title{
Resumen
}

El presente artículo describe la organización de las funciones en la literatura infantil y juvenil cubana contemporánea, según las tensiones contextuales y, en especial, las políticas culturales a partir de 1959. Señala cómo inicialmente las funciones se adecúan a la política cultural establecida de forma oficial. Explica el posterior reacomodo y el nuevo orden impulsado por una política cultural protagonizada por autores y editores interesados en promover derechos de la niñez y la juventud, con independencia de los discursos oficiales. El análisis ha dado muestras de cómo las tensiones y prioridades sociales, extraliterarias en su mayor parte, quedan codificadas en la organización de las funciones de la literatura infantil y juvenil, de manera que esta se convierte en evidencia sobre la sociedad y sus complejidades, y los modos en que las instituciones y actores sociales canalizan y tramitan sus expectativas y preocupaciones respecto a las jóvenes generaciones. Prestar atención a estos fenómenos, no siempre explícitos en las fuentes de información, es relevante a la hora de estudiar la infancia y de poner la LIJ a disposición de sus destinatarios.

Palabras clave: literatura infantil y juvenil, funciones literarias, política cultural, Cuba.

\begin{abstract}
Social tensions and priorities, mainly extra literary, are codified in the organization of literary functions. Consequently, literary functions become pieces of evidence about society and its complexities, and about the way in which institutions and social actors convey and manage their expectations and concerns. This article shows how organization of functions in Cuban contemporary literature for children has varied since 1959 according to its general context and, specifically, cultural policies over time. While functions initially adequate to the official cultural policy, there is a later reorganization with the emergence of a non-official cultural policy guided by authors and editors interested in promoting the rights of childhood and adolescents. Paying attention to these phenomena is relevant for childhood studies, and has an impact when providing books to children and young people.
\end{abstract}

Key words: literature for children, literary functions, cultural policy, Cuba. 


\section{Introducción}

Entre los argumentos que esgrimen los detractores de la literatura infantil y juvenil (en lo adelante LIJ) está un supuesto desbalance a favor de su orientación pragmática hacia el receptor niño y en detrimento del valor artístico (Herrera, 2018: 7). El devenir de este corpus, desde su surgimiento y hasta fecha reciente, hasta cierto punto justifica en parte los prejuicios de esta perspectiva que reduce la orientación pragmática a las misiones de hacerse comprensible y enseñar valores y contenidos. Se trata de una literatura que del cuento popular prosiguió a abrirse paso, no sin dificultad, entre fábulas morales, silabarios y catones, y luego desde los regazos de nodrizas e institutrices, cada quien con sus intereses. Un análisis de este fenómeno implica tener en cuenta las dinámicas que se establecen entre las funciones atribuidas a la literatura para ser tal, según los paradigmas y exigencias contextuales, incluidos aquellos en directa relación con la infancia y su lugar en la sociedad.

La infancia como grupo social se distingue por una serie de caracteristicas especificas de sus individuos y por ser inferior en cantidad al grupo de los adultos. Luego bien, en la estructura de cualquier sociedad funciona como una minoría típica, en posición diferenciada y sujeta tanto a la marginación como al paternalismo. Al igual que los adultos, los niños están expuestos a condicionantes y dinámicas políticas, sociales, culturales, económicas, etc., aun cuando el estatus jurídico de menores pueda modularlas. Al mismo tiempo, la infancia, por sus caracteristicas, depende de los mayores $y_{1}$ en consecuencia, se subordina a estos. Se convierte no solo en la beneficiaria de sus cuidados, o la víctima de sus maltratos u omisiones, también es depositaria de sus expectativas. Lo mismo que en la literatura en general se disputan posiciones de poder y se gestionan las tensiones entre dominación y resistencia, en los procesos comunicativos en que interviene la LIJ se discuten posturas e intereses de chicos y grandes. La LIJ, por lo general escrita y gestionada por adultos, refleja la construcción de infancia y las prioridades respecto a ese grupo (0campo, 2018: 15-20).

El presente texto se ocupa de la organización de las funciones en la literatura infantil cubana contemporánea. Para esto presenta un sucinto repaso histórico a la disposición de las funciones en la literatura infantil universal. A continuación, expone cómo responden las funciones de la literatura infantil a las tensiones contextuales y, en especial, las políticas culturales que sustentan la formación sociopolítica de las jóvenes generaciones en Cuba a partir de 1959 hasta la actualidad. Por último, ofrece conclusiones sobre los ordenamientos que adoptan estas funciones en los distintos momentos a lo largo del periodo.

\section{Funciones de la literatura infantil. Equilibrios y temporalidad}

Variados han sido los sistemas de funciones literarias propuestos desde que el estructuralismo europeo organizara teóricamente la idea -ya presente en el formalismo ruso- de una interrelación entre la forma estética de la literatura y el papel que esta desempeña en la sociedad. No obstante, es con la tipología propuesta por Sergio Andricain (1989), asumida en el presente trabajo, que aparece por primera vez un sistema de funciones elaborado para la literatura infantil en específico.

A pesar de las diferencias entre los diversos sistemas de funciones, prevalece el consenso de que estas son propiedades intrinsecas de las obras especificas, canalizadas por una serie de contenidos y características formales, con la potencialidad de desplegarse en el acto comunicativo. Asimismo, los distintos autores han mostrado la convicción de que, aunque coexistan una serie de funciones, Ilámense prácticas o sociales, con la función estética o poética, la condición artística solo se garantiza con el predominio de esta última en tanto propiedad de producir en el receptor una experiencia de 
disfrute. Esta experiencia se basa en la emergencia de niveles complementarios de organización lingüística, la ficcionalidad, el desplazamiento respecto a la situación discursiva, y la dialéctica de respeto y trasgresión de los paradigmas literarios asentados en la sociedad en el momento de la recepción, aunque también depende en parte de que los receptores confieran el tipo de atención que es capaz de descubrir, aceptar y asumir, en determinadas condiciones contextuales, un texto como literatura. Pero, asi como las convenciones literarias varian a lo largo del tiempo, se transforman la organización de las funciones sociales y sus límites en la competencia con la función estética (Herrera, 2018, 1-15).

En el caso de la literatura infantil, las construcciones acerca de la niñez han sido decisivas para sus paradigmas, en general, y para la organización de sus funciones, en particular. Mientras prevaleció la incomprensión de la infancia como una etapa específica de la vida y se asumió que el niño era un ser a entrenar para una completa y pronta inserción en la estructura social, fue la función formativa como propiedad de reproducir principios de un determinado sistema de valores, a menudo con el apoyo de la expresiva, trasmisora de sentimientos y emociones, especializada en conmover y así manipular, la que más se disputaba con la función estética el espacio de la literatura. Del mismo modo, el interés de superar lo antes posible las deficiencias cognoscitivas del niño llevaba a un reforzamiento de la función gnoseológica, aquella que permite trasmitir conocimientos e informaciones en general. Preteridas o ancilares, sin duda, quedaban las funciones utilitarias, aquella que favorece la comunicación con el niño, dada cierta correlación entre las caracteristicas del texto y las del receptor, y lúdica, aquella que posibilita el entretenimiento y la diversión del lector en el acto comunicativo (cfr. Andricain, 1989). Tanto es así que, a la luz de la actualidad, parte de lo que alguna vez fuera reconocido como literatura ha dejado de serlo.

La literatura infantil contemporánea, en sentido general, ha experimentado en las últimas décadas grandes cambios en sus paradigmas. Entre estos se destaca la referencia a realidades antes poco representadas, la complejidad de las narraciones, la profusión de elementos que precisan de un lector muy atento y activo para ser comprensibles, etc. (Herrera, 2018, 21-24; Sebastián, 2016).

Todo esto apunta a una actualización de las jerarquias entre las funciones literarias. En sentido general, las funciones estéticas y la lúdica se sustentan entre sí con los niveles de experimentación a que se accede y la voluntad de entretener al lector. La función gnoseológica se amplifica con la descripción social y se amortigua cuando las obras sugieren más que lo que representan, dando al lector la oportunidad de construir sentidos y completar lo no dicho. La función utilitaria, que como la gnoseológica se atenúa con la fragmentación y las elisiones, se manifiesta sobre todo en las obras para niños más pequeños a partir de la prioridad de lo concreto sobre lo abstracto, la estructura lineal, cierta brevedad, elementos afectivos, etc. La función expresiva mantiene una relevancia colateral, excepto en la poesía, mientras que la función formativa se promueve fundamentalmente desde valores implícitos y no expuestos de manera obvia. De hecho, cuando en una obra la función formativa aparece acentuada, la condición literaria se pone en duda.

\section{Ordenamientos en las funciones de la literatura infantil y juvenil cubana contemporánea}

La historia de LIJ cubana tiene un claro punto de inflexión en el triunfo de la revolución en 1959. El corpus anterior había estado marcado por su intermitencia, así en cantidad como en calidad. Sin embargo, el proyecto de construcción de una nueva sociedad, con grandes metas de desarrollo humano y donde las más jóvenes generaciones pasaron a ocupar un lugar central, generó el espacio 
para la creación y publicación sistemática de una literatura infantil consonante con las prioridades de su contexto.

Desde inicios de 1959 comenzaron las transformaciones culturales que harian posible el fortalecimiento del consenso en el marco del nuevo pacto social: creación de la Casa de las Américas (1959), la Imprenta Nacional (1959), el Consejo Nacional de Cultura (1961), la Unión de Escritores y Artistas de Cuba (UNEAC) (1961), Campaña de Alfabetización que permitiría declarar el país como territorio libre de analfabetismo en 1961, etc. Una iniciativa de tanto valor social como simbólico fue la conversión de cuarteles militares en escuelas. En enero de 1960, el líder Fidel Castro dedicó a la promoción de la lectura pasajes de su discurso de entrega del cuartel Moncada, enclave de gran importancia en la historia de la lucha revolucionaria, como plantel de educación. El discurso estimulaba la lectura como vía de formación para esa nueva generación que era necesario preparar con miras a la continuidad de una gesta revolucionaria que habia sido protagonizada por jóvenes (Castro, 1960).

La construcción de las jóvenes generaciones aparece aún más evidente y concentrada en el discurso de Fidel Castro en la clausura del primer congreso de la Asociación de Jóvenes Rebeldes, el 4 de abril de 1962. El líder les trasmite el cariño y la admiración de la dirección del país en virtud del papel que ya empiezan a asumir en la historia revolucionaria. Reafirma la condición de los jóvenes como "materia prima" (Castro, 1962), como continuadores y constructores de la obra de la revolución, llamados a ser mejores que sus antecesores. Pero también señala cómo esta concepción de las jóvenes generaciones está marcando las dinámicas de la conducción del país y también, en cierta medida, revela las claves de esa concepción y las reglas de esa dinámica.

Creer en los jóvenes determina una conducta, y la conducta de nosotros, dirigentes revolucionarios, no sería la misma; si no tuviésemos fe en los jóvenes, si no creyésemos en los jóvenes, nuestra conducta y nuestra actitud sería distinta (...) Creer en los jóvenes es ver en ellos además de entusiasmo, capacidad; además de energía, responsabilidad; además de juventud, ipureza, heroísmo, carácter, voluntad, amor a la patria, fe en la patria! (APLAUSOS), jamor a la Revolución, fe en la Revolución, confianza en sí mismos!, convicción profunda de que la juventud puede, de que la juventud es capaz, convicción profunda de que sobre los hombros de la juventud se pueden depositar grandes tareas (Castro, 1962).

Tomar como referencia los planteamientos del liderazgo revolucionario sobre la construcción de la niñez y la juventud es mucho más que atender la posición de un sector social específico a la hora de analizar la literatura para estas generaciones. En esos años las orientaciones de la alta oficialidad se adoptaban de una vez en el contexto de un fuerte consenso, la centralidad estatal nucleaba toda gestión cultural y los escritores estaban integrados a las instituciones. Si hubiere habido una construcción diferente de la niñez o la juventud, solo la estatal habría validado el tipo de ciudadanía efectiva y, en consecuencia, influyente en la relación literatura-destinatarios.

A la altura de 1962, la LIJ era ya una prioridad nacional corroborada por la creación de una editorial dedicada por entero a ella, la Editora Juvenil, que en 1967 se convertiría en Editorial Gente Nueva. Sus tiradas masivas engrosaron con creces el corpus que hasta entonces emergía en publicaciones periódicas y seriadas, así como en los libros de texto. Para finales de la década, a los libros de autores extranjeros ya se sumaban 27 de LIJ cubana. Esta literatura del patio se podía separar en dos áreas principales. La vertiente más copiosa, canalizada en los libros de texto del Ministerio de Educación y de la Editora Juvenil, también dirigida por pedagogos, tenía tendencia a representar las 
gestas históricas pasadas y recientes, de una manera realista, poco elaborada desde el punto de vista formal, y con intereses didácticos que llegaban a manifestarse de modo literal en algunos casos. La otra, difundida principalmente en revistas y periódicos, entre los que sobresalía el semanario Pionero por su calidad literaria, era más variada en sus temas, más experimental en la forma y de un mayor vuelo estético en sentido general (Rodríguez, 1996: 7-8).

Lo que se mantenía como cuerda común entre ambas vertientes era la ausencia de conflictos impactantes, pero reales en el país en ese momento, que no estuvieran en vías de solución o ya erradicados por la Revolución. Era el nacimiento de una literatura que de manera progresiva iría sublimando la imagen de la infancia y la juventud cubanas, tal como la del contexto en que estas se desarrollaban. Aun así, algunos cultivadores de la segunda vertiente experimentaron temprano los límites de la política cultural del momento; por causas institucionales e ideológicas, ajenas a la condición literaria, el equipo de redacción del semanario Pionero fue desintegrado en 1969 (Gutiérrez, 1989: 39; cfr. Vian, en Pérez, 2006: 66-67).

La relevancia de la formación político-ideológica estuvo presente en los documentos finales y, por tanto, en las acciones subsecuentes, de importantes eventos en la Cuba de inicios de los años setenta. Son los casos del Primer Congreso de Nacional de Educación y Cultura, en 1971, y del Fórum sobre Literatura Infantil y Juvenil, en 1972, uno de cuyos carriles se titulaba: "El libro infantil y juvenil sobre la base de nuestra ideología". El primero, reconocido como el núcleo estructurador de la política cultural de su momento, respecto a la literatura en general, y el segundo, en especial para la LIJ, señalaban la necesidad de estimular la escritura acerca de la historia y los héroes cubanos. Aun cuando, al menos, en el segundo evento no fue apoyada de forma unánime esta prioridad político-ideológica, sí fue la que marcó la producción y difusión de LIJ en los años siguientes. Ambos eventos generaron concursos que incentivaron sobre todo lo que pudiéramos denominar como literatura momentánea (textos cuya literariedad no depende tanto de sus propiedades intrínsecas como de la validación coyuntural y, por tanto, efimera, por parte de los receptores), de autores que solo consiguieron posicionarse en ese peculiar contexto por su fértil acentuación de la función formativa, pero cuya calidad literaria no conseguiría validarse más allá de las circunstancias. Esto último se constata al consultar el Diccionario de autores de la literatura infantil cubana (Herrera y Estupiñán, 2014), donde nombres como Mercedes Fortes de la Osa, Elsa Hernández Costales, Elena G. Lavín, Elpidio Pasos Mederos y Nena Valdés Recio, apenas cuentan con obras posteriores o con crítica literaria que les preste atención.

Un ejemplo de literatura momentánea es el cuento "¿Por qué el aguinaldo floreció en julio?", de Mercedes Fortes de la Osa, premiado en el concurso La Edad de Oro en 1972. La obra, desarrollada en un círculo infantil (guardería), termina con los niños dando voces de "gloria eterna a los héroes" (Fortes, 1974: 25).

No obstante, esta prioridad general en lo formativo no solo caló en las obras de principiantes o aficionados coyunturales. Publicado en 1975, el libro El cochero azul de Dora Alonso, una de las más destacadas escritoras cubanas para todos los públicos, culminaba con sus personajes principales proclamando su "calidad de cubanos, revolucionarios y socialistas" (Alonso, 1975: 94). Otra prueba de cómo el énfasis formativo no resistió el paso del tiempo es el hecho de que la adhesión política de los personajes de El cochero azul ya no figure en posteriores ediciones de este libro, considerado un clásico de la literatura infantil cubana (cfr. Alonso, 2004: 75). Se trata, en este caso, de una expresión de literatura momentánea dentro de una obra mayor.

Si bien no sería atinado generalizar, puede afirmarse que como tendencia la LIJ cubana de la primera mitad de la década de los setenta se acerca a la vertiente realista e historicista de los años 
anteriores. Por su parte, sus intentos más ficcionales muchas veces estuvieron plagados de espacios poco logrados, personajes planos, sobre todo animales, y en ocasiones ciertos matices melodramáticos. En general en esta etapa el uso del lenguaje es pobre y lleno de diminutivos, y la composición es defectuosa (Bortolussi, 1990; Redonet, 1989). La LIJ de ese momento era el reflejo de una actitud general que promovía en los niños una ilusión de seguridad en todos los niveles de convivencia, desde la familia como proveedora de amor, hasta el proyecto de pais como garante de dignidad y crecimiento humano.

En términos de funciones, este panorama de la década de los sesenta y primeros años setenta se puede definir por la estrecha vinculación de las funciones gnoseológica y formativa vehiculadas por medio de la concentración en detalles y progresiones de lo histórico o lo cotidiano y sus dosis de adoctrinamiento. La función utilitaria se percibe en el excesivo empleo de diminutivos con que muchas obras de aquellos años pretendieron acercarse a una infancia subestimada. La función expresiva, dando soporte al resto, se evidenciaba en aquellos desbordamientos afectivos que promovían de manera desmedida la empatía narrativa y la compasión. La función estética solo conseguía dominar en una parte de la literatura propiamente dicha, o era reprimida por el resto de las funciones, como en lo que hemos llamado literatura momentánea.

La posición oficial respecto a las jóvenes generaciones no conocería en lo adelante grandes variaciones:

Ustedes viven también en una época de grandes luchas ideológicas entre la ideología de los trabajadores y la ideología de los burgueses explotadores, entre la ideología del socialismo y la ideología del capitalismo (...) Para esta estar a la altura de esta época, ustedes, los pioneros, tienen que alcanzar un nivel de cultura superior al de las generaciones anteriores (APLAUSOS). Por eso la Revolución presta tanta atención a la educación. No solo en su deseo de trabajar por el bienestar y la felicidad de los niños, sino también - una cuestión muy importante- de prepararlos para el futuro (APLAUSOS). (Castro, 1975).

No obstante, cierta separación entre política y cultura comenzó a proyectarse en las reglas del juego institucional. El panorama político-cultural de la isla experimentó cambios favorables a la expresión artística desde mediados de los años setenta, con un punto de giro señalado por la creación, en 1976, de un Ministerio de Cultura. Su forma de gestión ha sido más respetuosa de la actividad creativa y ha ido permitiendo espacios de decisión más descentralizados respecto a las altas esferas.

El clima institucional a partir de ese momento fue también el contexto para la fundación de instituciones (como la subsección de Literatura Infantil y Juvenil de la Unión de Escritores y Artistas de Cuba en 1985), la creación de publicaciones (como la revista En Julio como Enero en 1986), la celebración de eventos (como el Primer Coloquio Internacional de Literatura Infantil y Juvenil Cubana en 1988 y el Encuentro Nacional de Investigación y Crítica de la Literatura Infantil en 1989). Todo este movimiento favoreció el ejercicio crítico proclive a dinamizar y desautomatizar una LIJ que ya por sí misma iba ganando en variedad y libertad, con más espacio para la fantasia, con una poética menos comprometida con la política y más espontánea y novedosa desde el punto de vista estilístico (Redonet, 1989: 15-16, 21-24; Gutiérrez, 1989: 47). La forma balanceada en que las funciones sociales se acomodan por debajo de la función estética en ese momento es expresión de la madurez que la LIJ ha ido alcanzando desde el despegue de 1959. Lo que sí persistió incluso en medio de la diversidad de esos años fue la inclinación hacia situaciones ideales, donde nada importunaba la tranquilidad del 
niño o el joven cubano en su alli y entonces. No fue hasta finales de la década que aparecieron por primera vez libros que abordaban la carencia material, títulos que ponian en crisis el hogar, la escuela y la sociedad, principales ámbitos de la infancia (Cabrera, 2008: 667).

Los años noventa constituyeron un fuerte reto en general para el proyecto pais y en concreto para la vida cotidiana de los cubanos. La caída del campo socialista al que Cuba se hallaba integrado, a cuyo impacto se sumó el reforzamiento de la hostilidad del gobierno de los Estados Unidos hacia la isla, sumieron el país en una dramática crisis económica, social y de valores, que desde las esferas oficiales fue denominada "Periodo Especial en Tiempos de Paz". El escenario removió y generó fórmulas y estrategias de supervivencia, que alcanzaron desde legislaciones para la sociedad en general, hasta soluciones particulares como la emigración. Así, la vitalidad de la industria editorial cubana es apenas palpable en los primeros años noventa por cuestiones económicas, pero con el progresivo restablecimiento ya sus temas no pueden mantenerse ajenos ni a la complejidad del momento vivido, ni a sus prolongaciones.

Un aspecto de merecida mención en este análisis es el recorrido en Cuba de la construcción social que sobre las jóvenes generaciones promueve la Convención sobre los Derechos del Niño, entrada en vigor en 1989 y de la que el país fue un temprano signatario. Cuba, que ya tenía una tradición legal de protección a la infancia con su Código de la Niñez y la Juventud, se hizo vocera de la Convención pronto y por distintos medios, lo que coincide con el establecimiento de una oficina de UNICEF en el pais en 1992. Un ejemplo es que la televisión nacional insertó en su horario estelar spots con mensajes de bien público que divulgaban esta perspectiva más horizontal y dialógica en las relaciones entre adultos y niños, con especial énfasis en el respeto, en general, a la infancia y, en especial, a sus necesidades de información, participación y recreación, tres derechos presentes en la Convención. Estos spot se hicieron muy notorios por su novedad formal, conceptual y por la participación de los actores nacionales más populares en ese momento. Si bien no es posible que un sistema de valores se entronice con rapidez en una sociedad, la Convención debió calar con cierto brío en aquellos actores sociales polarizados hacia la infancia, entre ellos, escritores y editores.

Lo cierto es que tanto la gestión editorial, como la de otros productos culturales, van dando muestras de un mejor reconocimiento de que niños y jóvenes tienen un lugar por lo que son en ese mismo momento, aun si no llega a perderse el interés en su futuro desempeño social. Las obras a partir de ese momento se valoran por su capacidad para generar entretenimiento y/o reflexión, aunque no conlleven una trasmisión directa de valores. Ya para ese momento la estrategia comunicativa de las editoriales hacia sus destinatarios depende menos estrictamente de la visión de instituciones con mayor jerarquia, pues las decisiones cada vez están más descentralizadas y, en cualquier caso, el diálogo entre el alto liderazgo y la infancia es menos estrecho, constante y visible que a inicios de la revolución.

La LIJ cubana experimenta así desde finales de los noventa la continuación del giro iniciado justo antes de la entrada en la crisis del Periodo Especial. Aunque el corpus en general continúa ganando en variedad formal y temática, dentro de la diversidad comienza a distinguirse una nueva tendencia a volcarse sobre la realidad. Esta vez se trata de señalar aquellos aspectos menos satisfactorios experimentados por la infancia y de los cuales hasta entonces pareciera habérsele querido aislar, al menos, en la LIJ (Cabrera, 2008: 666; Tornés, 2009-2011: 108-109). De hecho, la LIJ pronto comienza a abrir el diapasón de cuestiones que por tradición eran consideradas como tabú en la escritura para estas generaciones (la enfermedad, la muerte, las drogas, la diversidad sexual, etc.) y se extiende con amplitud a fenómenos evadidos o tratados con reticencia incluso en el discurso dirigido a los adultos en ese momento (la desigualdad social por motivos de raza y género, la insuficiencia del salario, las 
estrategias familiares ilícitas para manejar la pobreza). Esto se constituye en una especie de política cultural desde abajo, construida entre autores y editores, y que fluye hacia los espacios de lectura, de modo independiente a los discursos oficiales, a no ser que los interpele para contradecirlos.

A pesar de que por esos mismos años venia fraguándose a nivel internacional lo que despuntaría luego como "boom de los temas difíciles" (cfr. Ocampo, 2014: 81-90), esta política cultural desde abajo puede entenderse como un fenómeno autóctono. En la primera década del siglo XXI y parte de la segunda, el acceso a internet en Cuba era reducido y no contaba con condiciones propicias para la descarga de libros. Por limitaciones económicas, todavía hoy apenas se importan libros y las editoriales nacionales no tienen solvencia para pagar derechos de autor a la altura de las tarifas internacionales, lo que obstaculiza la publicación de obras extranjeras contemporáneas. Tampoco existen los medios para que las personas naturales puedan acceder a compras online. Según esto, la proliferación de "temas difíciles" en el resto del mundo no puede haber tenido una influencia significativa en la producción literaria cubana de los últimos años noventa y la década siguiente.

Un hito en esta política cultural desde abajo ha sido la creación, en 2007, de la colección Veintiuno en el marco de la editorial Gente Nueva. La colección ha sido desde entonces una especie de crisol de toda esta literatura de calidad y con nuevas prioridades, que venía produciéndose desde las postrimerias del siglo XX. Su perfil fue concebido para aunar literatura contemporánea, cubana y extranjera, para niños, adolescentes y jóvenes, con "temas difíciles" o "tabú" y maneras de hacer desprejuiciadas, novedosas o atrevidas (Gente Nueva, 2011). En este empeño, Veintiuno consiguió publicar a autores cubanos que, de manera dispersa hasta ese momento, se ocupaban de las problemáticas de la infancia en la sociedad actual, tanto con nuevas ediciones de obras ya agotadas, como con ediciones príncipe. También logró negociar con reconocidos autores extranjeros la cesión de derechos de autor de libros antes publicados en otros paises, para una tirada de pocos ejemplares y de circulación solo nacional, lo que, aunque a un nivel leve, ha contribuido a diversificar el endogámico panorama de la LIJ en la isla.

Todos estos fenómenos, concepciones y dinámicas se reflejan de algún modo en la organización de las funciones en la LIJ. Por un lado, se observa mayor interés en estimular el disfrute del arte y el entretenimiento a través de este, traducido en temas, tratamientos y recursos propicios para un mayor peso de las funciones estética y lúdica, con frecuencia muy imbricadas. El respeto a las capacidades interpretativas de los lectores, refrendado en una LIJ más compleja, debilita la función utilitaria en los libros que tienen como receptor niños de la edad escolar y mayores, para las cuales la mayor apuesta radica en el grado de interés de los temas; en buena medida los recursos formales que viabilizan la función utilitaria quedan recluidos en la literatura para la infancia temprana.

De particular interés resulta el comportamiento de las funciones gnoseológica y formativa. Una parte considerable de la LIJ cubana de los últimos años, como se ha dicho, parece asumir el papel de poner a disposición de sus lectores aquellas informaciones que les conciernen, pero no van a encontrar en los discursos oficiales - como el discurso escolar o el de los medios- que a ellos se dirigen. Aunque con el cuidado de mantener un nivel estético que no demerite la condición literaria, las descripciones sociales provistas por esta literatura reflejan entornos de vulnerabilidad evadidos en la esfera pública, aunque constatables tanto en la vida cotidiana, como en las investigaciones sociales acerca de esta (0campo, 2018: 116). Mientras, el énfasis formativo, de la manera más bien explícita en que se producía hasta este momento, va transitando de forma paulatina hacia el libro de texto para fines curriculares, su espacio por excelencia según todo indica.

Sin embargo, también se pudiera interpretar que esa LIJ que expone la cruda realidad involucra un cariz formativo de nuevo tipo, pues se convierte en una suerte de entrenamiento para una par- 
ticipación puntual más consciente y responsable en el mundo que les ha tocado vivir. Esta renovada función formativa, sin embargo, se distingue con tres peculiaridades respecto a su comportamiento en décadas anteriores. En primer lugar, la sutileza en el empleo de recursos ya que los conflictos se explican por su propio desarrollo narrativo, más que por la presencia de juicios de valor; proposiciones polisémicas que potencian amplios rangos de sugerencia, en lugar de moralejas, sentencias o afirmaciones conclusivas; etc.. Asimismo, la concentración en el mundo de la infancia y la juventud, en su aquí y ahora, más que como ciudadanos del futuro. Por último, la ausencia de sujeción explícita al proyecto político ideológico del país.

\section{Conclusiones}

En la LIJ cubana contemporánea es posible identificar tres etapas que se decantan por una serie de indicadores: la dirección (desde el gobierno o desde actores sociales como escritores y editores) de las políticas culturales, la construcción de las más jóvenes generaciones, la calidad formal y las preferencias temáticas. La interrelación de estos elementos encauza las tendencias en la organización de las funciones literarias.

La primera etapa, de 1969 a 1975 aproximadamente, está marcada por construcciones y políticas culturales trazadas desde la conducción de la revolución y expresan su expectativa de que niños y jóvenes se conviertan en su relevo de una manera acorde a su ideología. Las funciones gnoseológica y formativa se presentan en una estrecha vinculación cuando asumen el rol de fortalecer la nueva sociedad, al reflejar las raíces históricas y las conquistas sociales del momento. La función utilitaria se percibe en un acercamiento paternalista que pone en duda la capacidad de niños y jóvenes para lidiar con literatura de calidad, sugerente y experimental. La función expresiva refuerza emociones, a veces a niveles melodramáticos. La calidad puede llegar a ser muy cuestionable, con una función estética que solo consigue predominar en una zona limitada de la producción literaria, o queda debilitada por el resto de las funciones, como en los casos recurrentes de literatura momentánea.

En la segunda etapa, entre los años 1976 y 1988, la LIJ va consolidándose y alcanzando una cierta madurez, lo que se evidencia en una mayor calidad formal y diversidad en los temas, aunque con el elemento común de que la niñez y la juventud se siguen representando ajenas a los problemas de su tiempo. La gestión editorial desde ese momento irá ganando cierta autonomía respecto a las jerarquias institucionales, mientras que la construcción de niños y jóvenes, aún con enfoque de futuro, se hace menos patente en la LIJ. En general, las funciones sociales se acomodan de manera equilibrada por debajo de la función estética.

La etapa de 1989 a la actualidad, con una producción de LIJ ya más consolidada y con paradigmas de calidad literaria mejor establecidos, evidencia una singular coherencia con los derechos de niños y jóvenes a recibir información y a participar en la sociedad. La tendencia a señalar desafíos que enfrentan estas generaciones en la sociedad y el tiempo en que viven, se puede considerar como una política cultural desde abajo, gestionada entre autores y editores. En este momento se otorga mayor relevancia a las funciones estética y lúdica. La función utilitaria se desplaza en especial a la literatura para la infancia temprana. Las funciones gnoseológica y formativa convergen en la misión de preparar a la infancia y la juventud como protagonistas de sus propias vidas en la adversidad de su momento. Sin embargo, esta nueva oleada formativa se distingue por la sutileza de sus recursos, la concentración en el presente y la neutralidad del compromiso político. 
El análisis ha dado muestras de cómo las tensiones y prioridades sociales, extraliterarias en su mayor parte, quedan codificadas en la organización de las funciones de la LIJ. Esta literatura, a menudo subestimada o desestimada, se convierte en un tipo de evidencia sobre la sociedad y sus complejidades, y la manera en que las instituciones y actores sociales canalizan y tramitan sus expectativas y preocupaciones. Se trata de información sustancial que a menudo escapa a las descripciones sociales oficialmente legitimadas, y que es relevante para todo aquel profesional inmerso en estudios de infancia, de políticas culturales, etc. Prestar atención a los indicadores de este fenómeno resulta indispensable a la hora de seleccionar LIJ de calidad para poner a disposición de niños y jóvenes. En la mayoría de los casos, esta selección es ejecutada por adultos y se precisa todo el rigor para no anteponer nuestros intereses a los de los destinatarios.

\section{REFERENCIAS BIBLIOGRÁFICAS}

ALONSO, D. (1975). El cochero azul. La Habana: Gente Nueva.

(2004). El cochero azul. La Habana: Pueblo y Educación.

ANDRICAÍN, S. (1989). Valores ideoestéticos prevalecientes entre autores de la literatura infantil cubana. En Julio como en Enero, Gente Nueva-Comité Cubano del IBBY, 9, 20-42.

BORTOLUSSI, M. (1990). El cuento infantil cubano: Un estudio critico. Madrid: Pliegos.

CABRERA, L. (2008). Panorama de la literatura para niños y jóvenes. En AA. W. Historia de la literatura cubana. Tomo III. La revolución (1959-1988) (pp. 666-673). La Habana: Letras Cubanas.

CASTRO, F. (1960). Nada hay más importante que un niño. Discurso de entrega del "Cuartel Moncada" al Ministerio de Educación el 28 de enero de 1960. La Habana: Departamento de Relaciones Públicas del Ministerio de Relaciones Exteriores. (1962). Discurso pronunciado en la clausura del Congreso de la Asociación de Jóvenes Rebeldes, en el stadium Latinoamericano, el 4 de abril de 1962. La Habana: Departamento de Versiones Taquigráficas del Consejo de Estado.

(1975). Ustedes son el relevo. Discurso pronunciado en la inauguración del campamento de pioneros José Martí, en
Tarará, 20 de julio de 1975. La Habana: Editorial Gente Nueva.

FORTES, M. (1974). ¿Por qué al aguinaldo floreció en julio? En AA. W. Cuentos para ti I, II y III (pp. 13-25). La Habana:

Gente Nueva.

GENTE NUEVA (2011). Plegable promocional de Colección Veintiuno. La Habana: Gente Nueva.

GUTIÉRREZ, J. A. (1989). Primeras impresiones sobre los aportes generacionales, las tendencias y temáticas visibles en la poesía infantil de la revolución cubana. En Julio como en Enero, 5(8), 27-56.

HERRERA, R. L. (2018); Panorama de la literatura infantil y juvenil. La Habana: Editorial Félix Varela.

HERRERA, R. L. y ESTUPIÑÁN, M. (2015). Diccionario de autores de la literatura infantil cubana. La Habana: Gente Nueva - Ediciones Unión.

OCAMPO, D. (2014). Libro infantil y juvenil. Formación de lectores. La Habana: Editorial Científico-Técnica. (2018). Carencia material y desigualdad social en la narrativa infantil cubana (años 90 a 2012). Regularidades semántico-discursivas. Tesis en opción al grado científico de Doctora en Ciencias Lingüísticas. Universidad de La Habana. 
PÉREZ, E. (2006). Yo prefiero escribir para la infancia. Entrevista a Ivette Vian Altarriba. En Pérez, E. El fuego sagrado de los dioses. Los escritores para niños se confiesan (pp. 64-74). Guantánamo: Editorial El Mar y la Montaña.

REDONET, S. (1989). Narrativa infantil(ista) e infanticida y la narrativa para niños y adolescentes en la literatura cubana. En Julio como en Enero, 5(8), 20-26.
ROdRígueZ, A. O. (comp.) (1996). Antología de la narrativa infantil cubana. La Habana: Editorial Gente Nueva.

SEBASTIÁN, Raquel (2016). Manual de literatura infantil y educación literaria (Vol. 22). Ed. Universidad de Cantabria.

TORNÉS, E. (2009-2011). El cuento cubano entre 1980 y 2010. En Anuario LL. Estudios Literarios, (40-42), 103-120. 
